Recent surface reflectance measurement campaigns with emphasis on best practices, SI traceability and uncertainty estimation

This article has been downloaded from IOPscience. Please scroll down to see the full text article. 2012 Metrologia 49 S21

(http://iopscience.iop.org/0026-1394/49/2/S21)

View the table of contents for this issue, or go to the journal homepage for more

Download details:

IP Address: 128.183.110.93

The article was downloaded on 24/07/2013 at 20:11

Please note that terms and conditions apply. 


\title{
Recent surface reflectance measurement campaigns with emphasis on best practices, SI traceability and uncertainty estimation
}

\author{
Dennis Helder ${ }^{1}$, Kurt Thome ${ }^{2}$, Dave Aaron ${ }^{1}$, Larry Leigh ${ }^{1}$, \\ Jeff Czapla-Myers $^{3}$, Nathan Leisso ${ }^{3}$, Stuart Biggar ${ }^{3}$ and Nik Anderson ${ }^{3}$ \\ ${ }^{1}$ South Dakota State University, Brookings, SD 57007, USA \\ 2 NASA Goddard Space Flight Center, Greenbelt, MD 20771, USA \\ ${ }^{3}$ University of Arizona, Tucson, AZ 85721, USA
}

Received 2 October 2011, in final form 6 December 2011

Published 2 March 2012

Online at stacks.iop.org/Met/49/S21

\begin{abstract}
A significant problem facing the optical satellite calibration community is limited knowledge of the uncertainties associated with fundamental measurements, such as surface reflectance, used to derive satellite radiometric calibration estimates. In addition, it is difficult to compare the capabilities of calibration teams around the globe, which leads to differences in the estimated calibration of optical satellite sensors. This paper reports on two recent field campaigns that were designed to isolate common uncertainties within and across calibration groups, particularly with respect to ground-based surface reflectance measurements. Initial results from these efforts suggest the uncertainties can be as low as $1.5 \%$ to $2.5 \%$. In addition, methods for improving the cross-comparison of calibration teams are suggested that can potentially reduce the differences in the calibration estimates of optical satellite sensors.

(Some figures may appear in colour only in the online journal)
\end{abstract}

\section{Introduction}

Radiometric calibration of optical remote sensing satellites after launch has been pursued using several methodologies including on-board lamp systems, solar and lunar observations, ground targets and simultaneous imaging using a wellcalibrated satellite sensor. Perhaps one of the most widely used methods is that of vicarious calibration where ground truth information is collected at a defined site describing the optical characteristics of the Earth's surface and the intervening atmosphere. These data are then applied to a radiative transfer code to predict top-of-atmosphere (TOA) radiance. This prediction is then compared with what the satellite sensor simultaneously observed when imaging that site and a calibration estimate is obtained. Even from this simple description, it is obvious that estimates of numerous parameters are necessary that are based on calibration of various instruments. One of the most important estimates is that of surface reflectance. At many optical wavelengths that are often considered, errors in measurement of this parameter translate to equal error in TOA radiance predictions. Thus, it is very important to have a good understanding of the error sources and uncertainties that are a part of this measurement.

To better understand surface reflectance measurements, two campaigns were conducted within six months of each other that involved a worldwide group of satellite calibration teams. The first was conducted in August 2010 at Tuz Gölü in central Turkey. This campaign was sponsored by the Committee on Earth Observation Satellites (CEOS) Working Group on Calibration and Validation (WGCV) and the European Space Agency (ESA), and was hosted by Tubitak Uzay, the national space agency in Turkey. Although other smaller field campaigns have been performed previously [1], this campaign was multi-national with calibration teams from ten different countries spanning the globe. During the ten days of this event, participants concentrated on repeated surface reflectance measurements at Tuz Gölü, and their instruments were also calibrated in laboratory conditions by representatives 
from the National Physical Laboratory, the national standards lab in the United Kingdom. The primary purpose of this campaign was to share methodologies, evaluate differences in procedures and develop 'best practices' for obtaining surface reflectance. Results from this effort were reported at IGARSS 2011 in Vancouver, Canada [2-6].

Based on lessons learned from the Tuz Gölü campaign, a second campaign was undertaken in March 2011 by three teams from the United States: the University of Arizona Remote Sensing Group (RSG), South Dakota State University (SDSU) and Goddard Space Flight Center (GSFC). The purpose of this campaign was to build upon the experience at Tuz Gölü to develop improved procedures for measuring surface reflectance, better estimate the associated uncertainties, and to develop recommendations for future global calibration coordination interactions. Similar to the Tuz Gölü campaign, it involved both laboratory and field measurements. In addition, a more highly developed experimental procedure was implemented for the field campaigns in an effort to sort out effects due to operator, groups, instruments, illumination geometry and also radiative transfer processing.

Following sections of this paper report on the Arizona field campaign first since it has not been described elsewhere, and then the Tuz Gölü campaign results are briefly presented. A discussion section comparing the two campaigns follows, and the paper ends with conclusions and recommendations.

\section{Arizona field campaign}

\subsection{Description}

On 8 to 9 March 2011, a joint field campaign was conducted on the University of Arizona's campus in Tucson, Arizona. The university's Remote Sensing Group (RSG) hosted the event and provided the targets that were used for surface reflectance measurements. This location was chosen due to the pristine sky conditions that normally occur during this time of the year, and because of RSG's substantial experience in vicarious calibration. In addition, all three groups' Spectralon reflectance panels were calibrated in the RSG laboratory.

The methodologies for obtaining surface reflectance are quite similar among the three groups. Two major pieces of equipment are used: a spectrometer and a calibration panel. Each group uses the FieldSpec spectroradiometer (commonly called an 'ASD') produced by Analytical Spectral Devices, Inc. [7]. These systems cover the wavelength range from $350 \mathrm{~nm}$ through $2500 \mathrm{~nm}$ in approximately $1 \mathrm{~nm}$ increments. Five ASDs were used (two from RSG, two from SDSU and one from GSFC), each equipped with an $8^{\circ}$ field of view foreoptic (except one from SDSU had a $5^{\circ}$ foreoptic) and configured as a backpack for field use. The second major piece of equipment is a diffuse reflectance panel, commonly made of Spectralon [8]. These panels form the calibration basis for the surface reflectance measurement. They are normally calibrated by the supplier or, as was the case in this campaign, they can be calibrated by a third party (RSG). In the case of the Arizona campaign, multiple targets were used, both natural

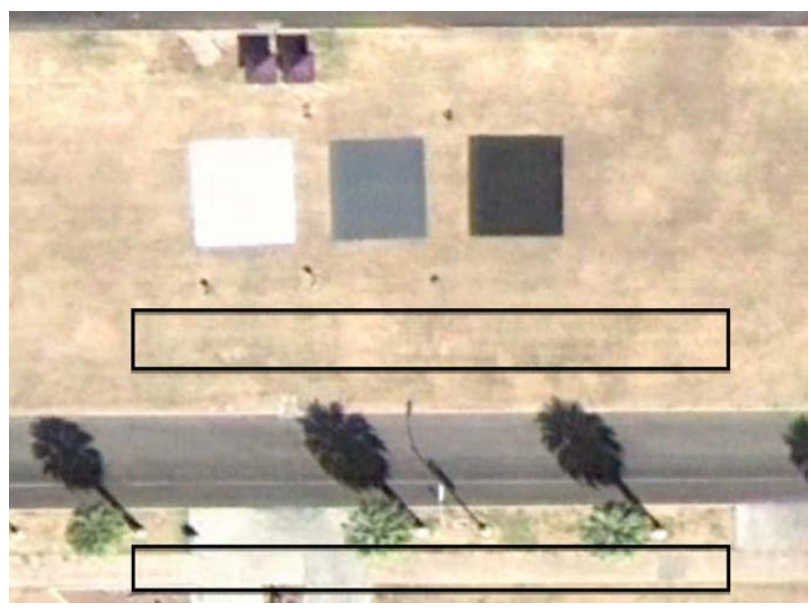

Figure 1. Layout of the targets used during the Arizona campaign. The $48 \%, 8 \%$ and $2 \%$ Tracor tarps are shown in the upper half of the figure. The grass target and concrete sidewalk target are shown by the black rectangles in the middle and lower portions of the figure, respectively. Calibration panels were located between the tarps and the grass target.

and man-made. Three Tracor tarps were deployed, roughly $8.5 \mathrm{~m} \times 8.5 \mathrm{~m}$, with nominal reflectances of $48 \%, 8 \%$ and $2 \%$. In addition, two natural targets were utilized-a concrete sidewalk and a grass strip. Figure 1 illustrates the positioning of all targets. Due to size constraints, and to maintain focus, this paper will describe the work done by the SDSU team using the $48 \%$ reflectance target.

\subsection{Procedure}

The procedure followed by all groups on both 8 and 9 March is as follows.

(1) All ASDs were warmed up for greater than $2 \mathrm{~h}$ prior to data acquisition to achieve thermal stability.

(2) Tracor tarps were deployed each day prior to data acquisition. Calibration panels were deployed immediately prior to the first data acquisition of each day. They were also covered between data acquisitions to avoid UV exposure.

(3) At the beginning of each data acquisition, the ASDs were optimized and 10 spectra of the calibration panel were acquired.

(4) Approximately 30 spectra of the $48 \%$ Tracor tarp were obtained by walking the perimeter of the tarp.

(5) The calibration panel was again viewed by the ASD and 10 spectra obtained.

(6) Steps 4 and 5 were repeated for the $8 \%$ and $2 \%$ Tracor tarps.

(7) 40 to 60 spectra of the grass target were obtained by walking along the edge of the target.

(8) The calibration panel was again viewed by the ASD and 10 spectra obtained.

(9) Spectra of the concrete sidewalk target were obtained in a manner analogous to the grass strip.

(10) Lastly, the calibration panel was viewed by the ASD and 10 spectra obtained. 


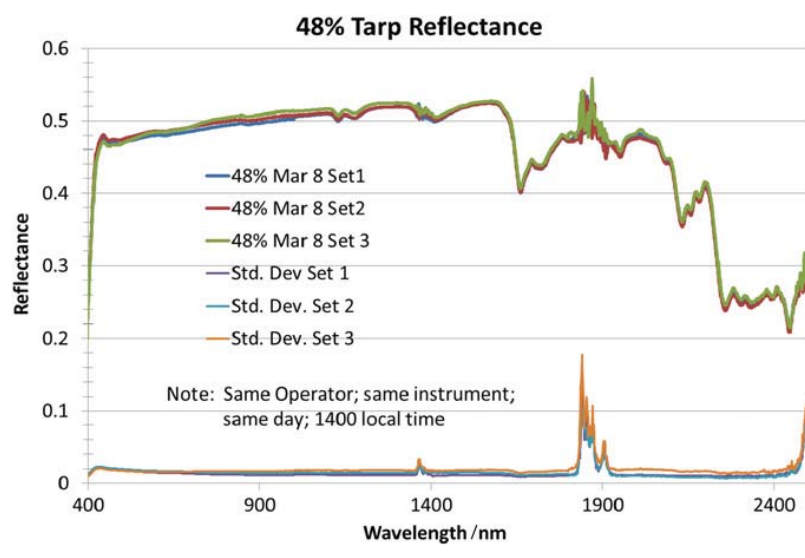

Figure 2. Spectral reflectance of the $48 \%$ Tracor tarp measured by operator \#1 on 8 March using ASD \#16004. Standard deviation of the measurement (each spectrum is an average of 30 measurements) is also shown.

48\% Tarp: \% Difference from Mean Reflectance;

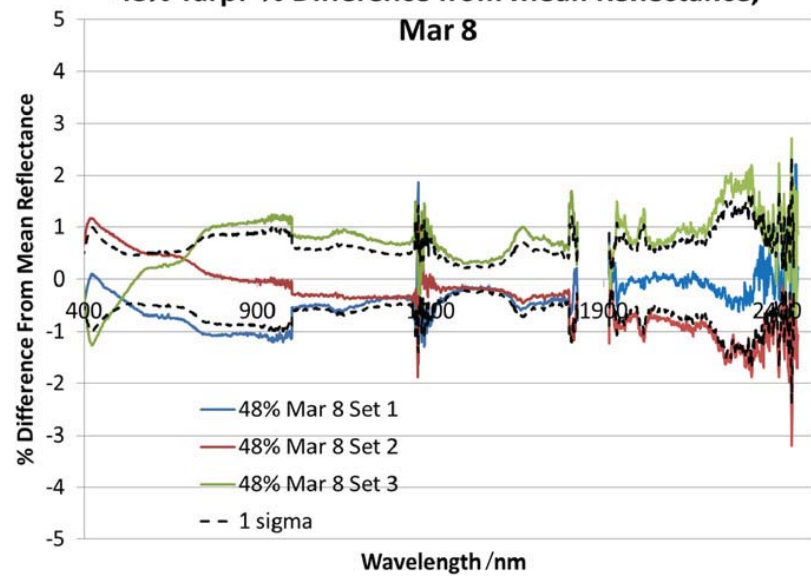

Figure 3. Percentage difference from mean reflectance measured in figure 2.

The entire procedure took approximately $45 \mathrm{~min}$ to complete and was replicated.

\subsection{Results}

Although a large amount of data were obtained, only those results collected by the SDSU team will be presented in an effort to understand uncertainties contributed by the operator, the instrument, and from collecting data on two different dates. SDSU collected data with three operators, two ASD spectrometers, one calibration panel, on both 8 and 9 March. Operators \#1 and \#2 were very experienced personnel, whereas operator \#3 had only minimum experience using an ASD during a field campaign. Of the two ASD instruments, \#16004 was a well maintained and calibrated instrument used regularly, while \#6219 was a 'backup' instrument that had seen little usage over the past five years. Atmospheric conditions were very similar on both dates.

Figures 2 and 3 illustrate the results obtained from operator \#1 using ASD \#16004 while measuring the surface reflectance of the $48 \%$ tarp three times on 8 March. Several features are immediately apparent from an inspection of figure 2. First the tarp reflectance is smooth and averages approximately $48 \%$ from $400 \mathrm{~nm}$ to $1600 \mathrm{~nm}$. At higher wavelengths the reflectance is not as smoothly varying and decreases to a reflectance level of $25 \%$. Also, the measurements are very consistent and nearly on top of each other, especially at the longer wavelengths. Figure 2 shows the standard deviation of the average measurements (each measurement is the average of approximately 30 spectra). The prominent feature on this plot is that the standard deviation of each measurement is consistently under 0.02 reflectance units, or about $4 \%$ in the VNIR. This result is essentially independent of wavelength, even though the target is darker at the longer wavelengths. In addition, there are three prominent features where the standard deviation is substantially larger than 0.02 . The first two features, roughly located at $1375 \mathrm{~nm}$ and $1850 \mathrm{~nm}$ are due to the presence of atmospheric water absorption features. Even in a desert climate, water vapour varies dramatically spatially and temporally. Thus, these features are present in all measurements of this type, and satellite imaging of the Earth's surface is normally not done at these wavelengths. Hence, for purposes of typical land imaging satellite calibration measurements, these spectral features can be ignored. In following charts they will be omitted for clarity. The third prominent spectral feature occurs at wavelengths greater than approximately $2400 \mathrm{~nm}$. These large variations are due to a decrease in the sensitivity of the ASD FieldSpec radiometer. Hence, since these results are due to limitations in the instrumentation, they will also be largely ignored in the following results and discussion.

Figure 3 shows the percentage deviation of each average spectrum in figure 2 from the mean of the three spectra. Thus, it represents a measure of the reproducibility of surface reflectance made under these conditions. The key result to note here is that the percentage differences are largely under $1 \%$. This result strongly indicates the limit of what is possible in field surface reflectance measurements using one operator with a well characterized instrument under optimal field conditions. In addition the type A standard uncertainty is also shown (black dotted line) and is under $1 \%$ at almost all wavelengths.

The next scenario to be explored is the situation of one operator/instrument combination used on multiple dates. This situation is indicative of what level of precision one calibration team is capable of producing in comparing multiple surface reflectance measurements. Results are shown in figure 4. In this plot the average spectrum of the $48 \%$ tarp from the two dates is shown, along with the percentage difference between these two measurements. Again, with the exception of the three spectral regions mentioned previously, the difference between the two measurements is at or below $1 \%$. Hence, the reproducibility of the measurement is the same as for a single operator on a single date with a similar atmosphere.

The next situation to be addressed is where there are two operators with two ASD instruments recording surface reflectance measurements on the same date. In this example, operators \#1 and \#2, who are both experienced personnel, are compared. Results are shown in figure 5. Here the difference between the two measurements is slightly larger-at least $1.5 \%$ 


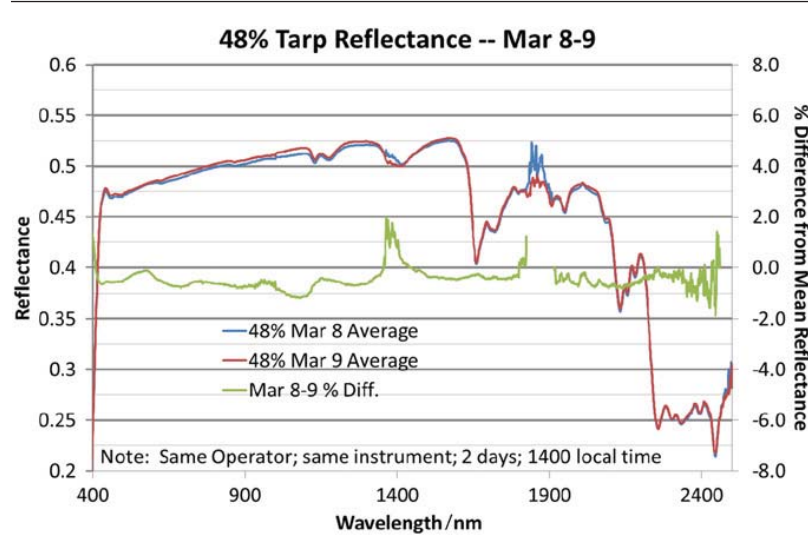

Figure 4. Surface reflectance as measured by one operator/instrument combination on two consecutive dates (red and blue curves). The percentage difference between the two measurements is shown by the green curve and is essentially at or below $1 \%$.

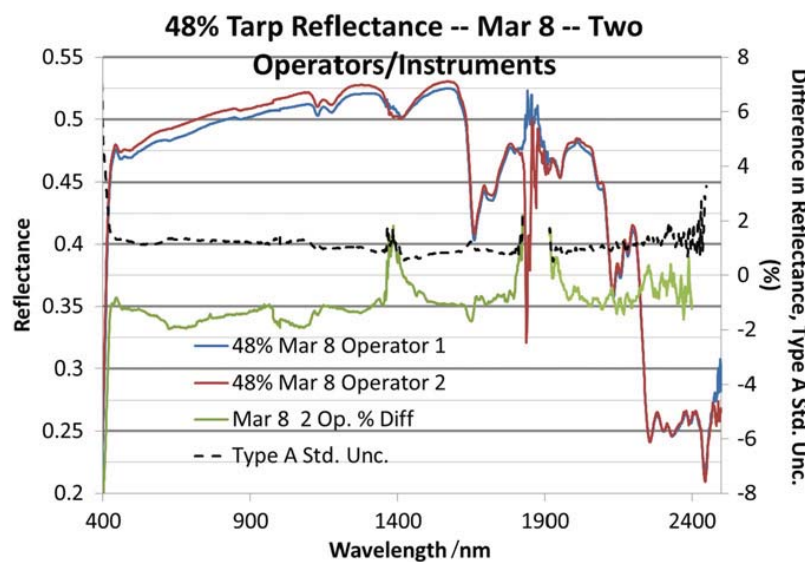

Figure 5. Surface reflectance for the $48 \%$ tarp as measured by two operators and two instruments on the same day. Percentage difference between the two is shown by the green curve. The standard deviation of the measurements (in \%) is shown by the dotted black line.

at some wavelengths, perhaps approaching $2 \%$. Thus, with multiple operators and instruments the uncertainties increase. The type A standard uncertainty, given by the black dotted line, is virtually constant at $1 \%$.

Figure 6 illustrates the scenario of two operators using the same instrument on two consecutive dates. In this case, operators \#2 and \#3 are compared, and operator \#3 is a relatively inexperienced person. The ASD instrument used is the backup instrument. In this situation the reproducibility is again between $1 \%$ and $2 \%$, while type A uncertainty is essentially at $1 \%$.

If all combinations are considered, the reproducibility of measurements from three operators using two instruments on two consecutive dates can be evaluated. These results are shown in figures 7 and 8 for clarity. Figure 7 shows the average surface reflectance as measured by each of the three operators. In this figure, the type A uncertainty (shown in black) increases from $1 \%$ but is still under $1.5 \%$. Figure 8 shows the difference of each of those average spectra from the mean value. Here it

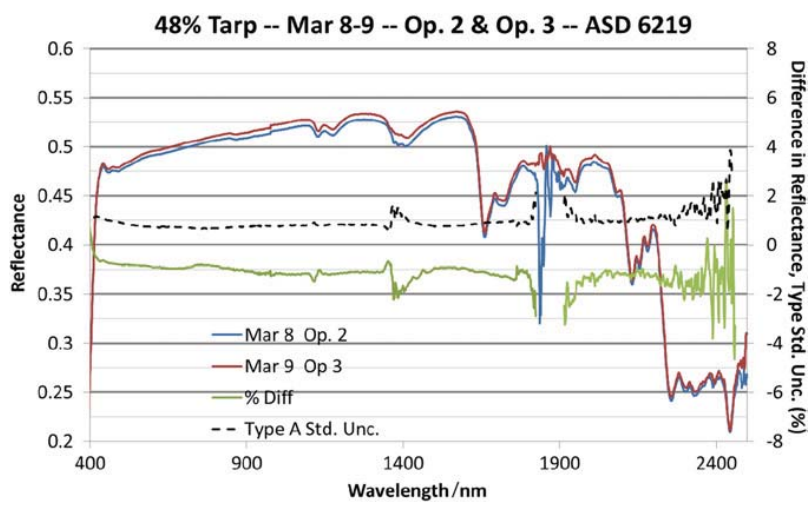

Figure 6. Surface reflectance measurements of the $48 \%$ tarp from two operators using the same instrument on two consecutive dates. Reproducibility is $1 \%$ to $2 \%$ as shown by the green curve, and the type A standard uncertainty is shown by the black dotted line.

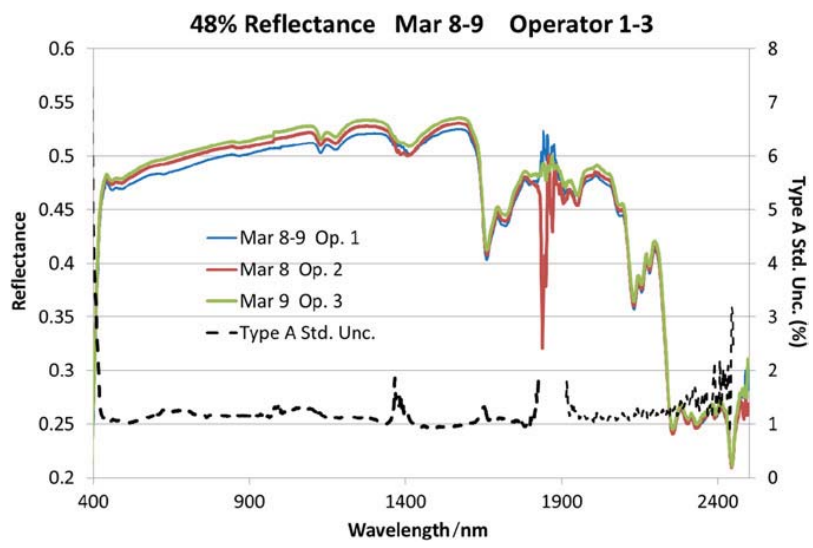

Figure 7. Average surface reflectance measurements of the $48 \%$ tarp as obtained by three operators, using two ASD spectrometers, on two consecutive dates.

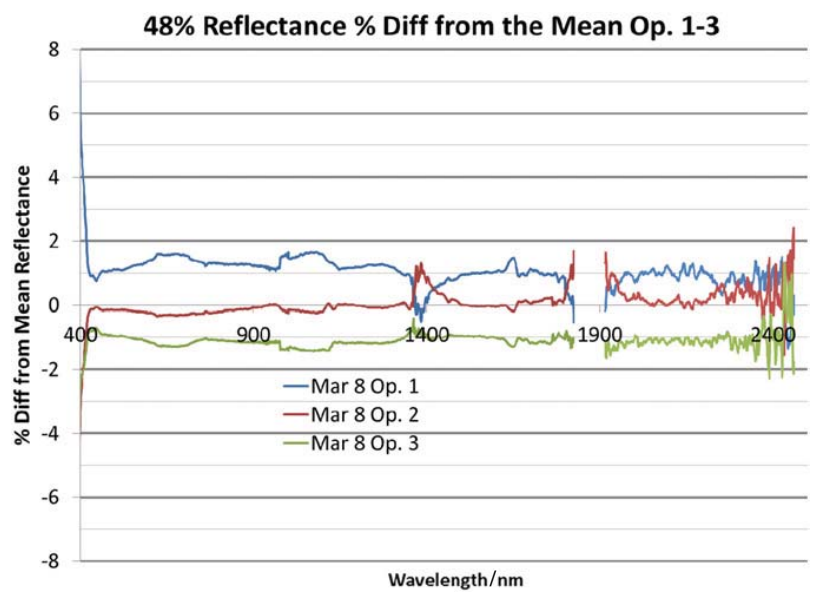

Figure 8. Percentage difference from the mean surface reflectance measurment recorded by three operators.

is clear that reproducibility has increased in value to $2 \%$. Thus, as can be seen through this series of experiments, as the number of operators and instruments increases, the reproducibility of the measurement becomes worse. 
Recent surface reflectance measurement campaigns

Table 1. Spectralon panel calibration uncertainties (as a percentage) as a function of wavelength.

\begin{tabular}{lllllllll}
\hline & \multicolumn{7}{c}{ Wavelength/nm } \\
\cline { 2 - 9 } & 445 & 485 & 560 & 657 & 863 & 1372 & 1611 & 2206 \\
\hline Lamp effects & 0.5 & 0.5 & 0.5 & 0.5 & 0.5 & 0.5 & 0.5 & 0.5 \\
Stray light & 0.07 & 0.06 & 0.05 & 0.04 & 0.03 & 0.02 & 0.02 & 0.01 \\
Lamp current uncertainty & 0.09 & 0.08 & 0.06 & 0.05 & 0.04 & 0.02 & 0.02 & 0.01 \\
Lamp current stability & 0.07 & 0.06 & 0.05 & 0.04 & 0.03 & 0.02 & 0.02 & 0.01 \\
Lamp current uncertainty & 0.09 & 0.08 & 0.06 & 0.05 & 0.04 & 0.02 & 0.02 & 0.01 \\
Lamp current stability & 0.4 & 0.4 & 0.4 & 0.4 & 0.4 & 0.4 & 0.4 & 0.4 \\
Alignment & 0.5 & 0.4 & 0.3 & 0.2 & 0.15 & 0.1 & 0.1 & 0.1 \\
Lamp ageing and drift & & & & & & & & \\
Reference effects & 0.1 & 0.1 & 0.1 & 0.1 & 0.1 & 0.1 & 0.1 & 1.0 \\
RF spectral change & 0.33 & 0.33 & 0.33 & 0.33 & 0.33 & 0.31 & 0.31 & 0.33 \\
NIST uncertainty in RF & & & & & & & & \\
Instrumentation & 0.5 & 0.4 & 0.2 & 0.16 & 0.13 & 0.1 & 0.1 & 0.1 \\
Spectral uncertainty & 0.03 & 0.03 & 0.03 & 0.03 & 0.03 & 1.0 & 1.0 & 1.0 \\
HP34970A/Lock-in uncertaintyyyyyyyyyyyyyyy & 0.5 & 0.45 & 0.4 & 0.3 & 0.3 & 0.1 & 0.1 & 0.1 \\
Detector/amplifier SNR & 0.5 & 0.45 & 0.4 & 0.3 & 0.3 & 0.1 & 0.1 & 0.1 \\
Detector/amplifier SNR & 0.2 & 0.2 & 0.2 & 0.2 & 0.2 & 0.2 & 0.2 & 0.2 \\
Stability & 0.5 & 0.5 & 0.5 & 0.5 & 0.5 & 0.5 & 0.5 & 0.5 \\
Repeatability & 0.1 & 0.1 & 0.1 & 0.1 & 0.1 & 1.0 & 0.1 & 0.1 \\
Transmittance & & & & & & & & \\
& 1.4 & 1.3 & 1.1 & 1.0 & 1.0 & 1.7 & 1.4 & 1.7 \\
Total & & & & & & &
\end{tabular}

\subsection{Panel calibration}

Fundamental to the surface reflectance measurement is the calibration of the Spectralon panels used as references for the ASD field spectrometers. Any uncertainties associated with the panels must be added to the total uncertainty of the measurement. As mentioned previously, calibration of these panels by the manufacturer is often used. For these groups, however, the panel calibration was performed by the RSG calibration laboratory. Because of the laboratory nature of this calibration, uncertainties associated with it are reasonably well defined and estimated. Table 1 shows the uncertainties from the RSG laboratory.

While a detailed discussion of table 1 is beyond the scope of this paper, a few observations are pertinent. Panel calibration is performed by measuring the reflectance of a reference panel and comparing that reflectance to the panel being calibrated. Because of this, some entries in table 1 are repeated (for example, 'Lamp current uncertainty'). Table 1 also clearly indicates the spectral dependence of the calibration. Lastly, note that the uncertainty due to transmittance at $1372 \mathrm{~nm}$ is an order of magnitude larger than at all other wavelengths. This is because of the water absorption feature present at this wavelength, and the difficulty in measuring relative humidity in the laboratory leads to this large $1 \%$ uncertainty. The bottom line with respect to calibration panel uncertainties is that they total from $1 \%$ to $1.7 \%$ depending on wavelength.

From the standpoint of field calibration methodologies for satellite calibration, the uncertainties present in the laboratory calibration of reflectance panels can be thought of as systematic in nature and would, therefore, be classified as type B uncertainties. If one adds together the uncertainties due to panel calibration and field measurement reproducibilities, and assuming they are uncorrelated, an overall uncertainty for surface reflectance can be obtained as shown in table 2. The table clearly indicates that minimum uncertainties occur when using a single operator at wavelengths from $560 \mathrm{~nm}$ to $863 \mathrm{~nm}$. Worst case results occur with multiple operators at longer wavelengths (1372 $\mathrm{nm}$ through $2206 \mathrm{~nm}$ ).

\section{Tuz Gölü field campaign}

\subsection{Description}

The Tuz Gölü field campaign was conducted from 13 August through 23 August 2010 and involved a total of 13 different teams from around the world, including SDSU [2]. The primary goals were:

- Evaluate differences in field instrument primary calibrations;

- Evaluate differences in methods for characterizing and assigning 'radiometric value' to a site, for multiple view angles;

- Establish formal traceability of the Tuz Gölü reference site based on an evaluation of all comparison results;

- Establish 'best practice' guidance and/or knowledge of variance between methodologies;

- Provide a multi-satellite sensor comparison linked to the ground calibration derived from the multi-team comparison;

- Identify the minimum and ideal specifications for characterization/instrumentation for a CEOS 'reference standard'.

Tuz Gölü is located in central Turkey and is a salt lake bed approximately $21 \mathrm{~km}$ wide $\times 33 \mathrm{~km}$ long. It is covered with water most of the year, but dries out during the summer months of July and August. Figure 9 is a satellite image of the 
Table 2. Estimates of total uncertainty associated with Arizona field campaign surface reflectance measurements as a function of wavelength and operator/instrument combination.

\begin{tabular}{|c|c|c|c|c|c|c|c|c|c|}
\hline & & \multicolumn{6}{|c|}{ Wavelength/nm } & \multirow[b]{2}{*}{1611} & \multirow[b]{2}{*}{2206} \\
\hline & & 445 & 485 & 560 & 657 & 863 & 1372 & & \\
\hline $\begin{array}{l}\text { Total panel uncertainty } \\
\text { Field campaign uncertainty }\end{array}$ & $(\%)$ & 1.4 & 1.3 & 1.1 & 1 & 1 & 1.7 & 1.4 & 1.7 \\
\hline $\begin{array}{l}\text { Single operator/ } \\
\text { instrument/day }\end{array}$ & 1 & 1.7 & 1.6 & 1.5 & 1.4 & 1.4 & 2.0 & 1.7 & 2.0 \\
\hline $\begin{array}{l}\text { Single operator/ } \\
\text { instrument/two dates }\end{array}$ & 1 & 1.7 & 1.6 & 1.5 & 1.4 & 1.4 & 2.0 & 1.7 & 2.0 \\
\hline $\begin{array}{l}\text { Two operators/ } \\
\text { single instrument/two dates }\end{array}$ & 1.5 & 2.1 & 2.0 & 1.9 & 1.8 & 1.8 & 2.3 & 2.1 & 2.3 \\
\hline $\begin{array}{l}\text { Two operators/ } \\
\text { two instruments/one date }\end{array}$ & 2 & 2.4 & 2.4 & 2.3 & 2.2 & 2.2 & 2.6 & 2.4 & 2.6 \\
\hline $\begin{array}{l}\text { Two operators/ } \\
\text { two instruments/two dates }\end{array}$ & 2 & 2.4 & 2.4 & 2.3 & 2.2 & 2.2 & 2.6 & 2.4 & 2.6 \\
\hline $\begin{array}{l}\text { Three operators/ } \\
\text { two instruments/two dates }\end{array}$ & 2 & 2.4 & 2.4 & 2.3 & 2.2 & 2.2 & 2.6 & 2.4 & 2.6 \\
\hline
\end{tabular}

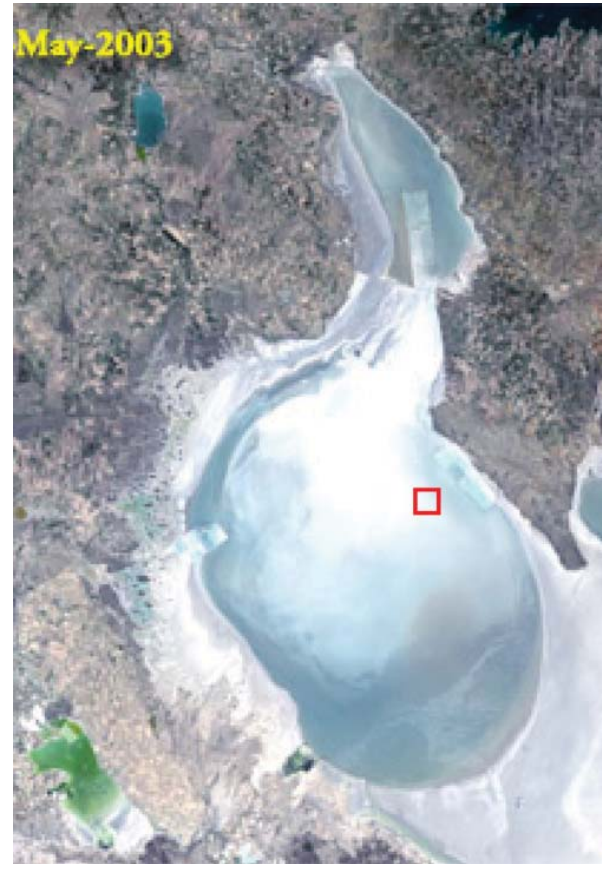

Figure 9. Satellite image of Tuz Gölü in central Turkey. The small red box indicates the location of the field campaign site.

lake with the small red box indicating the location of the field campaign.

The test site for this campaign was organized into eight small sites adjacent to one another that were each $100 \mathrm{~m} \times$ $300 \mathrm{~m}$ in size. In addition, a larger $1 \mathrm{~km} \times 1 \mathrm{~km}$ was present as a representative footprint for coarser resolution sensor systems such as the MODIS sensors. Each team was to measure the surface reflectance of each target once during the campaign. In order to better ascertain the repeatability of surface reflectance measurements that was possible at this site, the SDSU team elected to measure one of the small sites (designated as 'M1') each day. In addition, the SDSU team defined a small area on a corner of the M1 site (designated 'M1 Strip') that was
$5 \mathrm{~m} \times 30 \mathrm{~m}$ in size and measured that strip at precisely the same time each day (identical illumination geometries) for a total of eight measurements. The location of the M1 strip was chosen for maximum spatial uniformity. For purposes of comparison with the Arizona field campaign, only the results from the M1 Strip will be discussed here.

\subsection{Procedure}

The procedure that was followed for measurements at Tuz Gölü was similar to what was done in Arizona. That is, the ASD was 'warmed up' for $2 \mathrm{~h}$ so that it was thermally stable during the measurement period. The calibration panel (the same panel and ASD were used for both campaigns) was viewed by the ASD, and then the M1 Strip was walked. Approximately 30 spectra were collected each day. The M1 strip was the first site collected each day and represents the optimal opportunity for repeatable measurements during this campaign.

\subsection{Results}

Figure 10 shows the reflectance measurements that were collected. It is immediately apparent from the figure that in the visible wavelengths the Tuz Gölü lake bed and the Tracor $48 \%$ tarp are similar. That is, both are quite bright ranging from $40 \%$ to $60 \%$ reflectance. However, at the longer wavelengths, while both targets have lower reflectance, the Tuz Gölü site is much darker. At wavelengths greater than $2000 \mathrm{~nm}$ the Tuz Gölü site reflectance is approximately $5 \%$ while the Tracor tarp reflectance is $25 \%$. Secondly, fairly consistent measurements were made on each date with the exception of 18 August where the measurement is noticeably higher than the others. This anomaly was reported by other teams that day, but the source of the difference is unknown. There were indications that the surface was 'wetter' in the mornings and it is possible this was the cause on the 18th. But a weather front also moved through the region that day and could be another reason for the anomaly [3].

The left plot in figure 11 shows the deviation of each daily measurement from the mean of all surface reflectance 


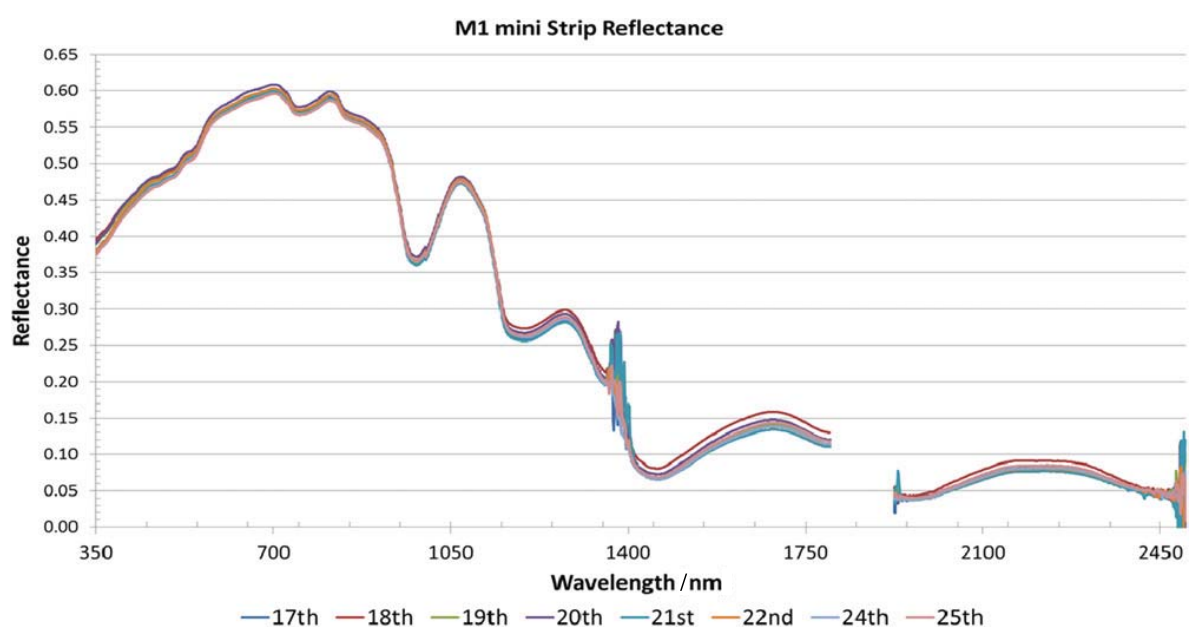

Figure 10. Surface reflectance measurements of the M1 Strip recorded from 17 August through 25 August 2010 at Tuz Gölü, Turkey.
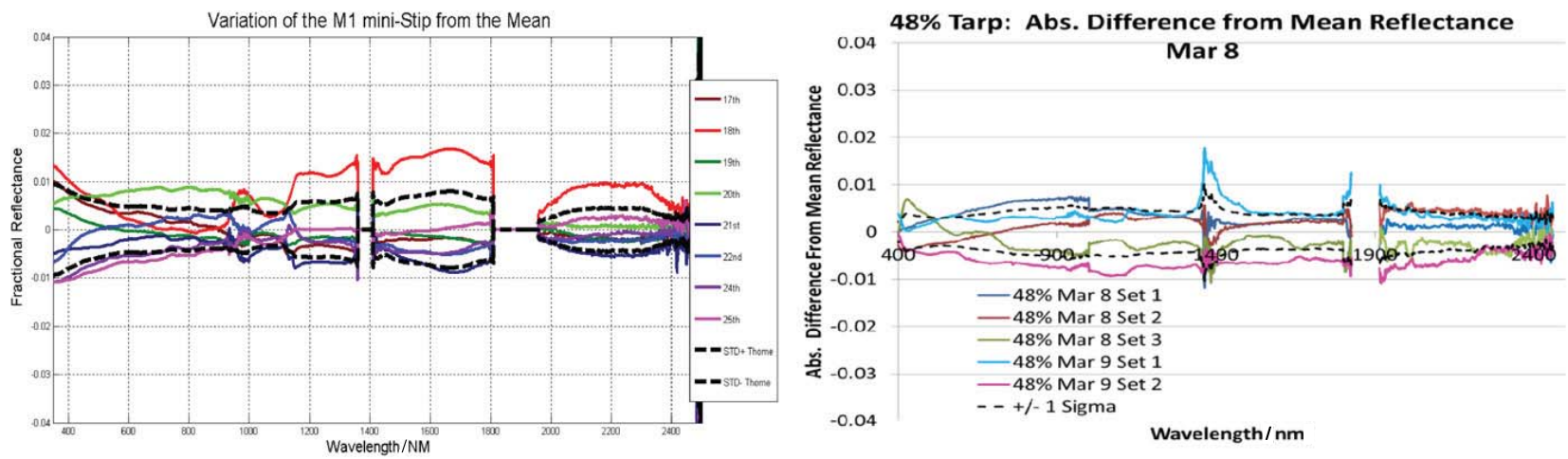

Figure 11. Comparison of the repeatability of surface reflectance measurements between the M1 Strip at Tuz Gölü and the $48 \%$ Tracor tarp at Arizona. Vertical scales are in deviation from the mean reflectance in absolute units.

measurements of the M1 Strip (including 18 August). In this plot it is clear that all measurements, except for the 18 August measurement, are within 0.01 reflectance units of the mean and this value represents a good estimate of the reproducibility of this measurement at Tuz Gölü. This plot also indicates that the 18 August measurement seems anomalous, but it was included in the standard deviation of the measurements which is also shown in the figure. On a percentage basis, the uncertainties are approximately $2 \%$ in the VNIR, $7 \%$ in the range from $1400 \mathrm{~nm}$ to $1800 \mathrm{~nm}$ and $12 \%$ from $2000 \mathrm{~nm}$ to $2500 \mathrm{~nm}$.

\section{Discussion}

Several observations can be made from a comparison of the Arizona and Tuz Gölü field campaigns. First, the Arizona field campaign had the advantage of operating in an excellent environment for field measurements of surface reflectance. The sky conditions, while not perfect, were substantially better than what was present at Tuz Gölü. Aerosol optical thicknesses were substantially less, and there was also less temporal variation. In contrast, the Tuz Gölü campaign had a longer duration and possibly more atmospheric variability for that reason. There are essentially no differences between operators and instruments as reported in this study. However, from an overall perspective, the Arizona campaign had more experienced operators than Tuz Gölü. This may have an effect on overall uncertainties as more and less experienced operators may increase uncertainties from what is reported here. A major difference between the two campaigns was in the surface reflectance of the target. While both targets were bright in the VNIR region, the Tuz Gölü surface was much darker in the SWIR. Thus, a major advantage of using a manmade target is better control of the spectral reflectance. Also related to this is spectral smoothness. While neither target was exceptionally smooth, man-made targets again offer the possibility for greater smoothness than natural targets. Lastly, having the same operator and instrument at both campaigns contributes well to experimental design, as does the fact that the two campaigns were only six months apart temporally. Thus, the sources of uncertainty in the measurements at the two locations are likely to be very similar.

Probably the most direct comparison of reproducibility between the two field campaigns can be observed comparing the plots in figure 11. In this figure the absolute deviation from the overall surface reflectance measurement made of the two targets is compared on a scale of absolute units. Here it is obvious that all measurements are well within a maximum deviation of \pm 0.01 reflectance units independent of 
wavelength (with the exception of the anomalous 18 August date at Tuz Gölü in the SWIR). In addition, the standard deviation at both sites is essentially 0.005 units. Thus, for a given instrument and operator on multiple dates, the measurement uncertainties were independent of location and target. These data suggest what is currently possible with fieldbased surface reflectance measurements for in-flight optical satellite calibration using ground-based methods.

\section{Conclusions}

Several conclusions can be drawn from this simple comparison of two field campaigns. First, the reproducibility with field measurements of surface reflectance can be as good as $1 \%$ with an experienced operator and proven instrumentation. If multiple operators and/or instruments are used, the reproducibility increases to around $2 \%$ and is probably due to differences in operator technique (for example, slight differences exist in positioning of the ASD foreoptic during data collection). Calibration panel uncertainties range from $1 \%$ to $1.7 \%$ and vary spectrally. With respect to the field measurements being addressed here, this uncertainty could essentially be thought of as a systematic, or type B error, present due to the equipment being used. When these two errors are combined, total uncertainties are $1.5 \%$ to $2.5 \%$ depending on operators, equipment and wavelength. Because the calibration panels used in the Arizona field campaign were calibrated based on a NIST standard panel at the RSG lab, SI traceability was accomplished. These results were demonstrated by experienced teams using well characterized equipment.

Lastly, the results generated through the comparison of these two campaigns suggest an efficient method could be developed for comparison of the surface reflectance measurements made by calibration teams around the world. Essentially, instead of gathering multiple teams together for an intercomparison, the same result could be accomplished by using a standard target, perhaps a Tracor tarp similar to what was used in the Arizona campaign, and shipping it to various calibration teams. Each team could then conduct a 'campaign' around the measurement of this target that could emulate their respective methodologies for measuring surface reflectance. This could be done in a coordinated manner such that the number of teams viewing the tarp annually could be maximized. However, it would also be important to have one reliable laboratory characterize this common target on a regular basis to make sure its integrity is not comprised through shipping and usage. An approach of this type will increase the number of measurements being made without any apparent increase in the uncertainties attached to the measurements. This could provide a great aid to the satellite calibration community by increasing comparisons of satellite sensors and calibration teams, which would lead to a much better understanding of overall calibration of the sensors.

\section{Acknowledgment}

This work was undertaken through support from the Landsat Project Science Office at NASA's Goddard Space Flight Center.

\section{References}

[1] Johnson B C, Barnes P Y, O'Brian T R, Butler J J, Bruegge C J, Biggar S, Spyak P R and Pavlov M M 1998 Initial results of the bidirectional reflectance characterization round-robin in support of EOS Metrologia 35 609-13

[2] Ozen H, Fox N, Leloglu U, Behnert I and Deadman A 2011 The 2010 Tuz Gölü field campaign — an overview IEEE Int. Geoscience and Remote Sensing Symp. (Vancouver, BC, July 2011)

[3] Leigh L, Helder D, Behnert I, Deadman A, Fox N, Leloglu U, Ozen H and Griffith D 2011 Tuz Gölü site characteristics IEEE Int. Geoscience and Remote Sensing Symp. (Vancouver, BC, July 2011)

[4] Boucher Y et al 2011 Sepctral reflectance measurement methodologies for Tuz Gölü field campaign IEEE Int. Geoscience and Remote Sensing Symp. (Vancouver, BC, July 2011)

[5] Thome K and Fox N 20112010 CEOS field reflectance intercomparisons lessons learned IEEE Int. Geoscience and Remote Sensing Symp. (Vancouver, BC, July 2011)

[6] Deadman A, Behnert I, Fox N and Griffith D 2011 Laboratory panel and radiometer calibration IEEE Int. Geoscience and Remote Sensing Symp. (Vancouver, BC, July 2011)

[7] ASD Inc., 2555 55th Street, Suite 100, Boulder, CO 80301. Website: http://www.asdi.com/

[8] Labsphere, Inc., 231 Shaker Street, PO Box 70, North Sutton, NH 03260. Website: http://www.labsphere.com 